\title{
Two patients with a complete proximal rupture of the hamstring
}

\author{
Sebastiaan Floor · Alex H. van der Veen • \\ Roger J. Devilee
}

Received: 13 May 2009 / Published online: 18 August 2009

(C) The Author(s) 2009. This article is published with open access at Springerlink.com

\begin{abstract}
Two men visited our Emergency Room because of a water-ski-accident. At physical examination, there was hematoma at the upper leg with loss of strength at extension of the hip and flexion of the knee. Both patients had a palpable gap just distal of the ischial tuberosity. Further imaging by sonography and MR-scan showed a rupture of the proximal hamstring tendon. Treatment was operative refixation of the hamstring tendons at the ischial tuberosity. Aftertreatment consisted of brace for 4 weeks after operation. Both patients returned to their pre-operatively sports, though at a lower level. Surgical treatment of a complete proximal rupture of the hamstrings is recommended in case of sportive patients.
\end{abstract}

Keywords Hamstring - Tendon rupture - Refixation ·

Muscle tear

\section{Introduction}

An injury of the hamstring is one of the most common injuries of tendomyogen origin [1]. Normally, it is a partial injury at the proximal muscle-tendon junction [2]. A complete

S. Floor $(\bowtie)$

Leiden University Medical Center, Leiden, The Netherlands

e-mail: sebastiaan_floor@hotmail.com

A. H. van der Veen

Surgeon Traumatology, Catharina Hospital Eindhoven,

Eindhoven, The Netherlands

R. J. Devilee

Orthopaedic Surgeon, Catharina Hospital Eindhoven,

Eindhoven, The Netherlands rupture of the hamstring tendons is a rare injury among adult athletes.

The mechanism of injury is often a combination of forceful (hyper-)flexion of the hip with extension of the knee. Most patients complain of acute pain at the dorsal side of the upper leg. Besides the pain, they have a loss of function of the hip, less strength of the hamstring, and sometimes instability of the knee. Physical examination revealed eccymosis of the dorsal side of the thigh, with less strength at extension of the hip and flexion of the knee, and a palpable defect of the proximal hamstring musculature. Diagnosis can be confirmed by magnetic resonance imaging.

\section{Cases}

Two patients were surgically treated at our clinic because of a traumatic rupture of the proximal tendons of the hamstring.

\section{Patient A}

A 45-year-old man visited the emergency room because of a water-skiing accident. He was an inexperienced waterskier and fell with his knee in full extension and forced flexion of the hip. The patient complained of pain at the dorsal side of his thigh. The patient did not have a history of other trauma, chronic disease, or use of corticosteroids. He was an active sportsman, playing water polo at regional competitive level. At physical examination at the ER, there was loss of strength at flexion of the knee and extension of the hip. The thigh was swollen because of hematoma formation and the patient had compression pain at the ischial 
tuberosity. Ultrasonography was, because of massive hematoma, inconclusive. MRI-scan showed besides an impressive hematoma, a rupture of the biceps femoris, semimembranosus, and semitendinosus (Figs. 1 and 2). Operative exploration and reconstruction followed 11 days after injury.

\section{Patient B}

Patient B is a 44-year-old experienced water skier, who fell during mono-waterskiing with his knee in full extension and hyperflection of the hip. This patient was seen in the ER the same day. Patient B also did not have a history of

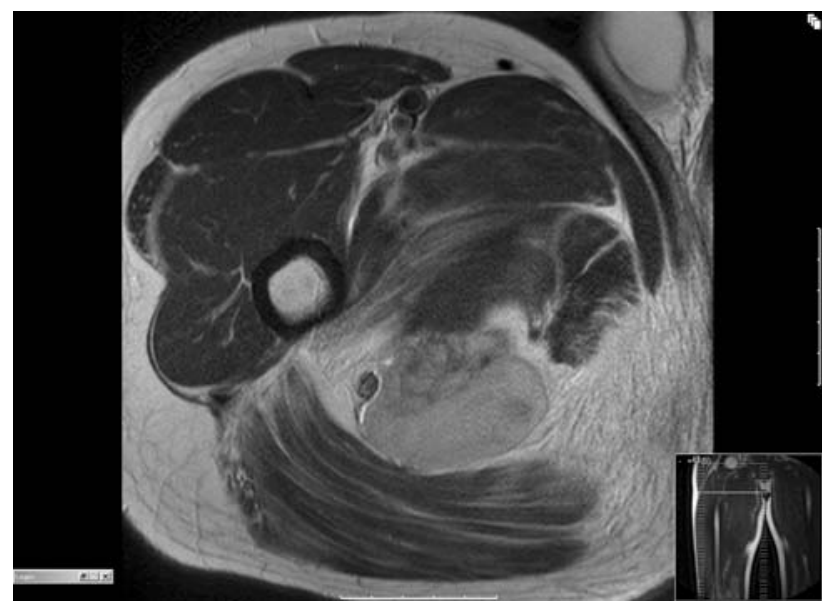

Fig. 1 Tranverse T2-weighted image of the right thigh. A massive hematoma is seen at the proximal part of the M. semitendinosus. The muscle belly of the long head of the M. biceps femoris is absent, confirming a rupture with retraction. A high signal of the tendon of the M. semimebranosus suspects a partial tendon rupture of this muscle

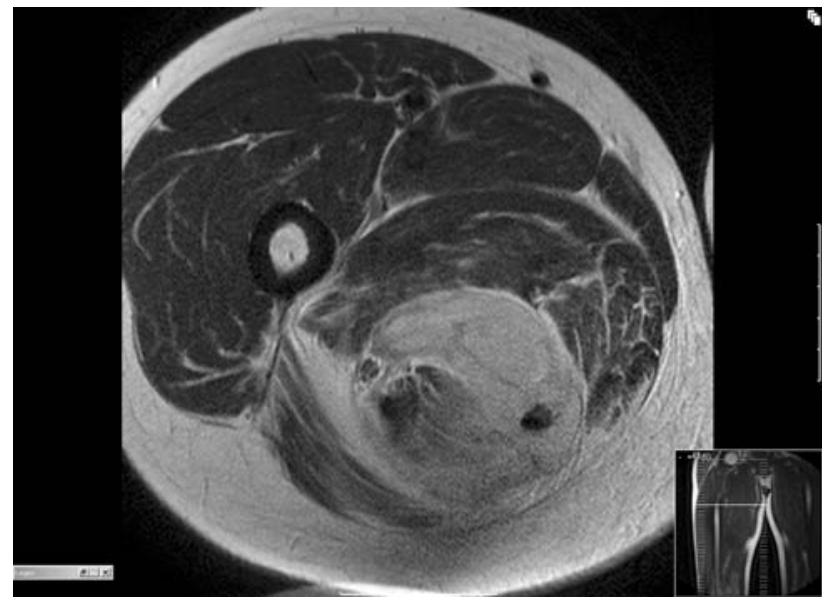

Fig. 2 Transverse T2-weighted image of the right thigh, a few centimeters distally of Fig. 1. Massive hematoma in the compartment of the M. semitendinosus and M. semimembranosus. The relationship between the sciatic nerve is clearly visualized other trauma, chronic disease, or use of corticosteroids. He was active in tennis, jogging at regional competitive level. Besides loss of strength, there was massive swelling of his thigh. Ultrasonography showed was suspect for a rupture of the proximal hamstrings. MRI-scan confirmed this diagnosis and showed a complete rupture of the proximal tendons of the biceps femoris, semimembranosus, and semitendinosus. This patient was operated 6 days after injury.

\section{Operation technique}

The same operation technique was used at both patients. Under spinal anesthesia, the patient was in a prone position. To approach the origin of the hamstrings, a midline longitudinal incision was made from the gluteal fold distally. The posterior femoral cutaneous nerve was indentified, which crosses the hamstrings from lateral proximal to medial distal (Fig. 3). Damage to this nerve causes annoying hypoesthesia of the thigh, especially during sitting. After identification of the sciatic nerve, the defect was visualized. At both patients, there was a complete rupture of the tendon of the long head of the biceps femoris with rupture of the both the semimembranosus and the semitendinosus at the origin (Fig. 4). The tendons were firmly attached to the ischial tuberosity with three bio-absorbable anchors (Fig. 5).

\section{After treatment}

Postoperatively, the reconstruction was protected by a brace (Fig. 6 ) with the hip immobilized in $0^{\circ}$ extension and the knee in $90^{\circ}$ flexion. The patients used the brace for 4 weeks, day and night (the patients were only able to lay

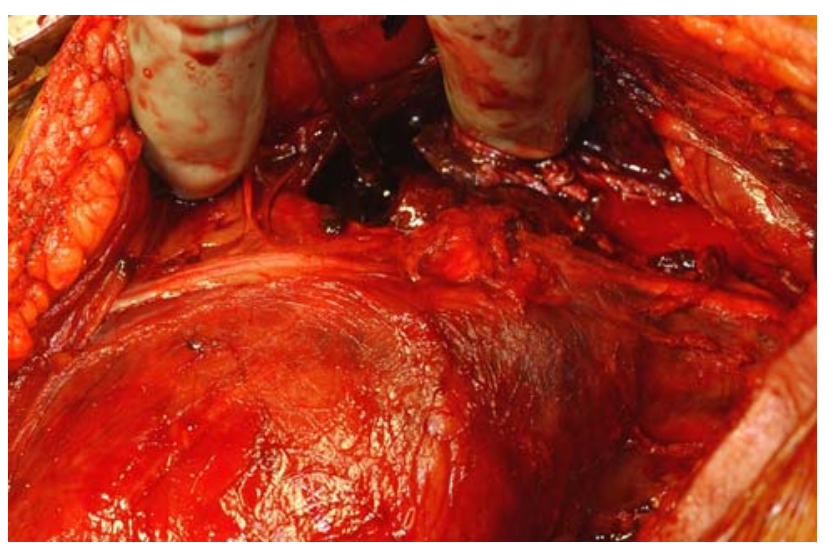

Fig. 3 Peroperative image of patient A. The posterior femoral cutaneous nerve was indentified, which crosses the hamstrings from lateral proximal to medial distal. Damage to this nerve causes annoying hypoesthesia of the thigh 


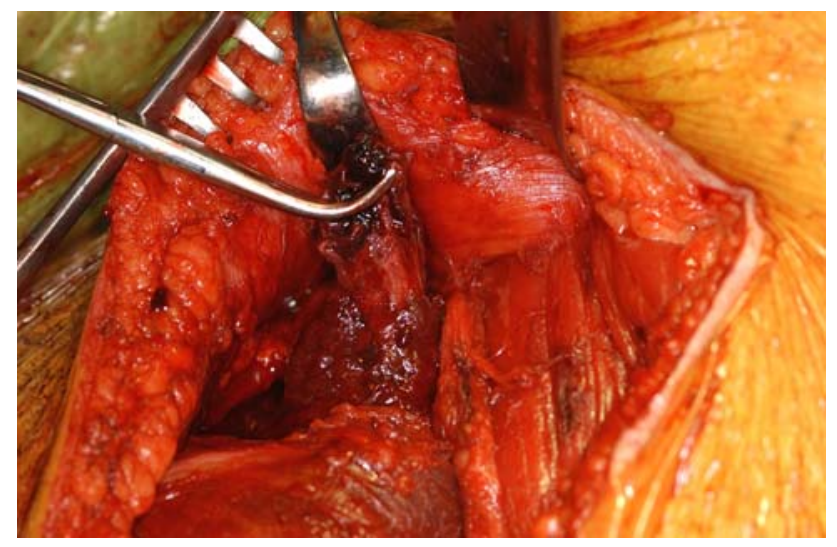

Fig. 4 Peroperative image of patient A. The ruptured tendons of the $M$. semimembranosus and $M$. semitendinosus before refixation to the ischial tuberosity

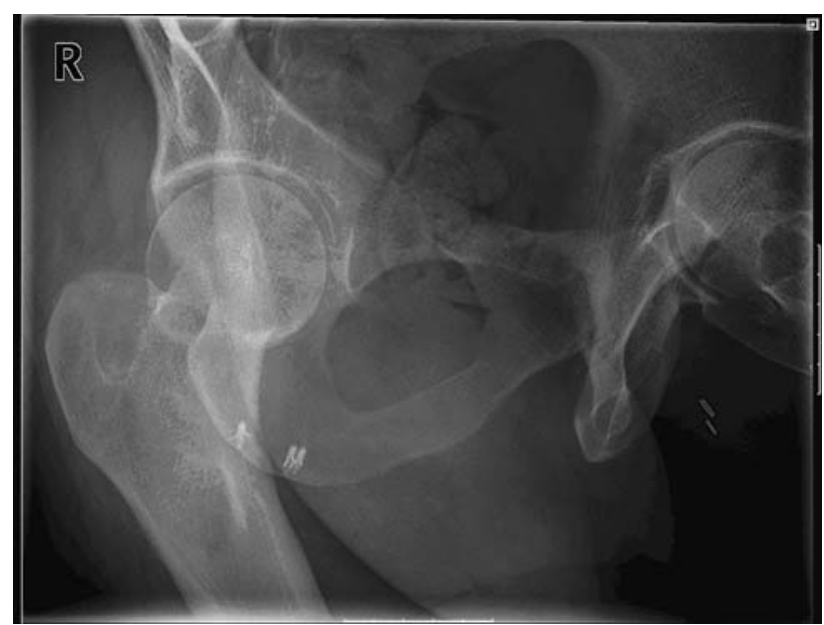

Fig. 5 Postoperative X-ray of the pelvis of patient A. Three bioabsorbable anchors attached the tendons to the ischial tuberosity

down in lateral position and walked with crutches). After 4 weeks, a physiotherapist started a program with practicing range of motion and strength of hip and knee. Patients were allowed to restart their sports 3 months after surgery. Patients used anticoagulants (Fragmine ${ }^{\circledR} 2,500 \mathrm{IU} /$ day) for 6 weeks.

\section{Results}

Both patients were seen, besides the regular controls, 16 months after operation for evaluation. They had at interview few complaints. Patient A had slight pain during sitting for a long time, while patient $\mathrm{B}$ had slight pain at sprinting. At physical examination, both patients showed no change in function comparing the operated leg with the healthy leg. The origin of the hamstrings was not painful at compression, and strength was at both sides equal. At daily work, patients did not had any restrictions, although they

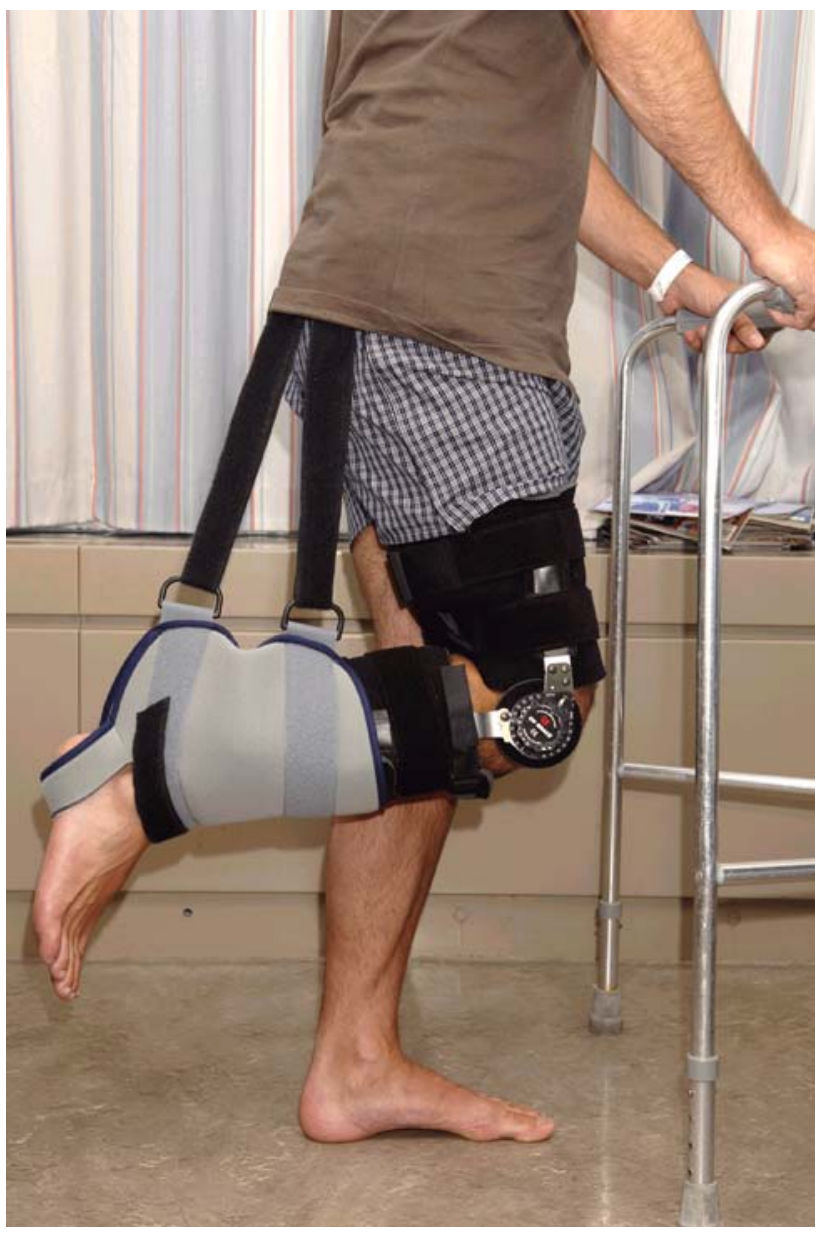

Fig. 6 Custom made brace to prevent flexion of the hip and extension of the knee. Both patients used this brace day and night to protect the refixation of the tendons

still performed their sports at a lower level. They both were satisfied with the result of their operation.

\section{Discussion}

Injury of hamstrings is one of the most frequent injuries at athletes. In most cases, it is a contusion of the muscle because of an indirect trauma, like during a sprint or a jump $[1,2]$. Conservative treatment of this contusion gives mostly excellent results. A complete rupture of the biceps femoris, semimembranosus, or the semitendinosus is on the other side a rare injury. Recently, a couple of small series were described with patients with complete hamstring ruptures. One case report described a complete rupture of the semimembranosus muscle at a tetraplegic patient after therapeutic stretching [3]. Controlled trials with operations versus conservative treatment are not published, because of the low incidence of the injury.

Our patients had a complete rupture of the hamstrings caused by a waterskiing accident. In literature, many cases 
of a hamstring tendon rupture caused by waterskiing are described [4-7]. A complete proximal hamstring rupture is in almost all cases caused by trauma. Patients complaint of pain at the back of their thigh. Flexion of knee and extension of hip is decreased.

On physical examination several days after trauma, swelling and ecchymosis is seen at the back of the upper leg because of hematoma formation. At the site of the origin of the hamstrings, there is a palpable defect. At testing strength of the leg, flexion of the knee and extension of the hip is decreased.

Besides ultrasonography, MRI-scan is advised to confirm diagnosis. Besides this confirmation, MRI gives information about the level of retraction and quality of the ruptured muscle.

Treatment of a proximal hamstring rupture can be operative or conservative. In a study of 12 complete and partial hamstring ruptures caused by waterskiing accidents, the conservative treatment was studied [8]. Seven patients were able to participate there pre-injury sports at a lower level. The other 5 patients were unable to run, and could not practice their sports. Because of the poor results of conservative treatment, we decided to operate patients with a proximal hamstring rupture with sportive ambitions.

Operative reconstruction of a proximal hamstring rupture can be done in an acute and chronic stadium. In general, results of operative treatment are better in the acute stadium, i.e., within 4 weeks after trauma, than older ruptures [4-7, 9-12]. At a longer existing rupture, there is retraction of the muscle stump. Reconstruction can be impossible if retraction of the stump causes a long distance between the stump and the ischial tuberosity. Reconstruction with tendon allograft to bridge the gap is described to solve this problem [13,14]. Another disadvantage of late operative treatment is scar formation around the sciatic nerve causing lesion of it during preparation. Quality of tendons and muscle tissue decreases in time because of increased fat content, as described earlier at rotator cuff muscle [15]. Because of these negative factors, acute reconstruction of the complete hamstring ruptures is advised.

One year after surgery both patients had no limitations in daily life activity. The patients continued their sports at competitive level, although they had not reached their preinjury level yet. An explanation for this shortcoming is that both patients restarted acting their sports at competitive level not long for our follow-up. In daily activities both patients did not have any complaints. Both patients were satisfied with the result of their operation in spite of the invalidating after treatment.

Results of operative reconstruction are often good. Patients could practice their sports in most cases at preinjury level 6-12 months after operation $[4-7,9,10,12$, 16]. In contrary were the results of conservative-treated patients [8]. Results of randomized, controlled studies are absent, but small series show better results with operative treatment, especially at patients with sportive ambitions.

Acknowledgments H.C.M. van den Bosch, Radiologist, Catharina Hospital Eindhoven, has contributed to this article.

Conflict of interest statement The authors declare that they have no conflict of interest.

Open Access This article is distributed under the terms of the Creative Commons Attribution Noncommercial License which permits any noncommercial use, distribution, and reproduction in any medium, provided the original author(s) and source are credited.

\section{References}

1. Agre JC (1985) Hamstring injuries: proposed aetiological factors, prevention, and treatment. Sports Med 2:21-33

2. Kujala UM, Orava S, Järvinen M (1997) Hamstring injuries. Current trends in treatment and prevention. Sports Med 23:397-404

3. Chua SG, Kong KH (2006) Complete semimembranosus rupture following therapeutic stretching after a traumatic brain injury. Brain Inj 20:669-672

4. Klingele KE, Sallay PI (2005) Surgical repair of complete proximal hamstring tendon rupture. Am J Sports Med 30:742-747

5. Cross MJ, Vandersluis R, Wood D, Banff M (1998) Surgical repair of chronic complete hamstring tendon rupture in the adult patient. Am J Sports Med 26:785-788

6. Orava S, Kujala UM (1995) Rupture of the ischial origin of the hamstring muscles. Am J Sports Med 23:702-705

7. Blasier RB, Morawa LG (1990) Complete rupture of the hamstrings origin from a waterskiing injury. Am J Sports Med 18:435437

8. Sallay PI, Friedman RL, Coogan PG, Garret WE (1996) Hamstring muscle injuries among water skiers. Functional outcome and prevention. Am J Sports Med 24:130-136

9. Brucker PU, Imhoff AB (2005) Functional assessment after acute and chronic ruptures of the proximal hamstring tendons. Knee Surg Sports Traumatol Arthrosc 13:411-418

10. Thomsen NOB, Jensen TT (1999) Late repair of rupture of the hamstring tendon from the ischial tuberositas-a case report. Acta Orthop Scand 70(1):89-90

11. Cohen S, Bradley J (2007) Acute proximal hamstring rupture. J Am Acad Orthop Surg 15(6):350-355

12. Sarimo J, Lempainen L, Mattila K (2008) Complete proximal hamstring avulsions: a series of 41 patients with operative treatment. Am J Sports Med 36(6):1110-1115

13. Folsom GJ, Larson CM (2008) Surgical treatment of acute versus chronic complete proximal hamstring ruptures. Am J Sports Med 36(1):104-109

14. Murray PJ, Lowe WR (2008) Achilles allograft reconstruction of a chronic complete proximal hamstring rupture. Knee Surg Sports Traumatol Arthrosc. [Epub ahead of print]

15. Warner JJP, Parsons IM (2001) Latissimus dorsi tendon transfer: a comparative analysis of primary and salvage reconstruction of massive, irreparable rotator cuff tears. J Should Elbow Surg 10:514-521

16. Chakravarthy J, Ramisetty N, Pimpalnerkar A, Mohtadi N (2005) Surgical repair of complete proximal hamstring tendon ruptures in water skiers and bull riders: a report of four cases and review of the literature. Br J Sports Med 39:569-572 